\title{
pensar outros possíveis entre infâncias e necropolíticas
}

\author{
ellen lima souza ${ }^{1}$ \\ universidade federal de são paulo, são paulo, brasil \\ orcid id: https:/ / orcid.org/0000-0002-7945-9353 \\ alexandre filordi carvalho ${ }^{2}$ \\ universidade federal de lavras, lavras, minas gerais, brasil \\ orcid id: https:/ / orcid.org/0000-0003-4510-9440
}

resumo

Ao se objetivar a publicação do presente dossiê, intenta-se colocar em cena uma série de investigações cujos desafios e cujas abordagens, problematizações e experimentações levem em consideração o amplo espectro da necropolítica. Entretanto, ao se enfatizar os lugares das infâncias contemporâneas em tal cenário, sublinha-se o complexo nódulo que as crianças negras ocupam na necropolítica. Numa via, pelo fato de serem, contra suas vontades, capacidades humanas e decisões, herdeiras de uma situação histórico-social de matriz necropolítica. As crianças negras, assim, nascem territorializadas num contexto necropolítico inequívoco. Em outra via, as crianças compõem relevante aceno na formação de estratégias de tensão e de modificação nos quadros necropolítico. Se as crianças aprendem a ser racistas, desde a mais precípua socialização, na ampla lógica necropolítica, também podem aprender a não ser racistas. Indagar por outros possíveis, tomando por centralidade as crianças, é atentar-se para toda experimentação que as crianças são capazes de empreender como desterritorialização necropolítica. Para tanto, sustenta-se que outros possíveis para uma comunidade de vida, movida por políticas de afetos, sensíveis às singularidades e diferenças humanas, produzindo valores para além da cova profunda da herança maldita colonial, não se faz sem a educação. Assim, a sucessão dos artigos que este dossiê apresenta, por perspectivas múltiplas e diferentes, com abordagens peculiares e preocupações próprias, tonalizando ênfases variadas e originais, traz um esforço coletivo de se produzir outros possíveis para as crianças no mundo contemporâneo.

palavras-chave: infâncias; necropolítica; outros possíveis; educação.

\section{pensar otros posibles entre infancias y necropolíticas}

resumen

Con el objetivo de se publicar este dossier, se intenta colocar en escena una serie de investigaciones cuyos retos y cuyas abordajes, problematizaciones y experimentaciones, lleven en consideración el largo espectro de la necropolítica. Todavía, al enfatizarse los lugares de las infancias contemporáneas en todo ese escenario, se subraya el complejo nódulo ocupado por los niños negros en la necropolítica. En una vía, pelo hecho de existieren, contra sus voluntades, capacidades humanas y decisiones, como herederas de una situación histórica-social de matriz necropolítica. Los niños negros nascen territorializados por un contexto necropolítico innegable. En otra vía, los niños componen relevante gesto en la formación de las estrategias de tensión y de modificación en los cuadros necropolíticos. Si los niños aprenden a ser racistas, a partir de la más precipua socialización, en la larga lógica necropolítica, también pueden aprender a no ser racistas. Cuestionar por otros posibles, teniéndose por centralidad los niños, es atentarse hacia toda experimentación que los niños son capaces de emprender como desterritoralización

\footnotetext{
1 E-mail: ellen.souza@unifesp.br

2 E-mail: afilordi@gmail.com
} 
pensar outros possíveis entre infâncias e necropolíticas

necropolítica. Para lográrselo, se sostén que otros posibles para una comunidad de vida, movida por políticas de afectos, sensible a las singularidades y diferencias humanas, produciendo valores más allá de la profunda herencia colonial maldita, no se hace sin la educación. Así, la sucesión de los artículos que este dosier presenta, desde múltiples perspectivas y diferencias de abordajes, conllevando preocupaciones propias, marcando énfasis variadas y originales, trae un esfuerzo colectivo de producirse otros posibles hacia los niños del mundo contemporáneo.

palabras clave: infancias; necropolítica; otros posibles; educación.

to think other possibilities between childhoods and necropolitics.

abstract

By publishing this dossier, it is intended to put in place a series of investigations whose challenges and approaches, problematizations and experiments take into account the broad spectrum of necropolitics. However, when emphasizing the places of contemporary childhoods in such a setting, it underlines the complex nodule that black children occupy in the necropolitics. In one way, because they are, against their will, human capacities and decisions, inheritors of a historical-social situation of a necropolitical matrix. Black children are born, thus, territorialized in an unequivocal necropolitical context. In another way, children make a relevant nod in the formation of tension and modification strategies in the necropolitical frameworks. If children learn to be racist, since the first socialization, in the broad necropolitical logic, they can also learn not to be racist. To inquire for other possibilities, taking children as centrality, is to pay attention to all the experimentation that children are able to undertake as a necropolitical deterritorialization.

For such, it is maintained that other possibilities for a life community driven by affection politic, sensitive to human singularities and differences, producing values beyond the deep pit of the cursed colonial heritage, are not possible without education. Thus, the succession of articles presented in this dossier, from multiple and different perspectives, with peculiar approaches and concerns of their own, emphasizing varied and original emphases, brings a collective effort to produce other possibilities for children in the contemporary world.

keyword: childhood; necropolitics; other possibilities; education. 
pensar outros possíveis entre infâncias e necropolíticas

É uma tarefa colossal o inventário do real Fanon, 2015, p. 167

Na década de 1950, Roger Bastide e Florestan Fernandes (2008) publicaram resultados parciais de uma extensa pesquisa acerca das relações entre negros e brancos na sociedade brasileira. Consideravam a expansiva metrópole da cidade de São Paulo um laboratório social. Entre as tensões da alforria tardia de 1888, pela qual os povos afro-brasileiros foram despejados nas cidades sem serem absorvidos como mão de obra especializada; a chegada de imigrantes europeus; a fixação de uma classe média branca e conservadora; o aprofundamento das desigualdades sociais e da violência nos centros urbanos, Bastide e Fernandes destacavam o cerco de um ciclo que nunca cessou de se desenvolver no Brasil.

Referido ciclo se apresenta da seguinte maneira. De um lado, "as indagações sociológicas comprovam que o 'branco' tende a apreciar o seu comportamento de forma muito benigna, como se the fosse possível escravizar o 'negro' e ficar imune à degradação dos mores [costumes], produzida pela escravidão" (Bastide; Fernandes, 2008, p. 19, grifos nossos). De outro lado, jamais como expressão oposta, porém complementar, o que os autores denominavam à época de preconceito de cor embora saibamos que se trata de racismo - funcionava numa modulação constante, sempre ao serviço da subjugação racial: "o preconceito de cor, cuja função era justificar o trabalho servil do africano, vai servir agora para justificar uma sociedade de classe, mas nem por isso vão variar os estereótipos antigos; mudarão apenas de finalidade" (Bastide; Fernandes, 2008, p. 21, grifos nossos).

Passaram-se décadas; mudamos de século e de milênio; alteramos inclusive o umbral epistemológico pelo qual noções, conceitos e chaves analíticas foram avançando nas abordagens, nas compreensões, nas problematizações e nas lutas contra o racismo. Contudo, parece-nos ser persistentes velhos costumes da época da senzala. Eles se estendem como uma semiótica racista que vai se atualizando violentamente na medida em que se evidencia que negras e negros estão longe de não padecerem todo tipo de degradação econômica, institucional, social, moral, física, psíquica e afetiva. Isso se casa perfeitamente com o racismo que se encaminha 
pensar outros possíveis entre infâncias e necropolíticas

conforme se alteram as finalidades de seu uso, manejo e aplicação numa sociedade que foi a última do planeta a abolir a escravidão. Segue o fato: no Brasil, "coexistem, lado a lado, a sobrevivência da sociedade escravista e inovações da sociedade capitalista" (Bastide; Fernandes, 2008, p. 21).

Enquanto a inovação da sociedade capitalista é benfazeja com a extensão da casa-grande brasileira, os herdeiros dos povos africanos passaram a experimentar a consequência-limite dessa mesma inovação capitalista. Ela se chama necropolítica. Trata-se de um complexo contexto vivencial pelo qual a vida passa por um gabarito sórdido de valorização conforme se sobressai a morte. Na necropolítica preponderase a experiência sócio-histórica por onde se normaliza a morte para vidas que não importam ser vividas em detrimento de outras (Mbembe, 2018 b). A necropolítica é um marcador racial inegável. A razão é muito simples: “o branco tende a defender sua posição de mando e direção" (Bastide; Fernandes, 2008, p. 222); o capitalismo é uma ordem oligárquica produtiva racialmente branca cujo esforço político resulta sempre em favorecer os seus interesses (Mayer, 2017); a fatia precarizada, vulnerável e carente da população, além de considerada improdutiva pelo neoliberalismo, é racialmente afrodescendente (Carvalho, 2020; Hosang; Lowndes, 2019)3; a direção política é racialmente branca e opera barreiras raciais na ascensão social dos negros e das negras, (Bastide; Fernandes, 2008; Kilomba, 2019).

Embora a chave analítica da necropolítica seja recente, a sua atuação sempre esteve latente nas estratégias coloniais de aniquilação, nos poderes totalitários e na extensão do racismo cotidiano. Exemplos abundam. Os próprios Bastide e Fernandes (2009, p. 199, grifos nossos) ao estudarem as estratégias de ajustamento e de absorção dos negros e das negras na sociedade dos brancos brasileiros, destacavam a imposição dos estereótipos raciais em detrimento aos que deveriam ser aniquilados juntamente à cultura e à associação ao traço de cor de pele. A necropolítica, desse ponto de vista, operou, no Brasil industrializado, como política

\footnotetext{
${ }^{3}$ No Brasil atual (Mões, 2021), para uma média de remuneração no valor de $\mathrm{R} \$ 3.388,00$ para um homem branco, o homem negro receberá $\mathrm{R} \$ 1.710,00$. Enquanto na média a mulher branca pode chegar a receber $R \$ 2.526,00$, a mulher negra receberá assustadores $R \$ 1.471,00$. Uma mulher branca ganha mais $48 \%$ que um homem negro; uma mulher negra ganha $57 \%$ menos que um homem branco e $42 \%$ abaixo de uma mulher branca. A diferença é tão alarmante que apenas entre negros e negras o abismo é menor, ou seja, uma mulher negra recebe $14 \%$ menos que o trabalhador negro, comprovando-se um achatamento racial na precarização salarial.
} 
de branqueamento, logo, de aniquilação das redes simbólicas afrocentradas. Eis a farta síntese desse idílio:

A política de embranquecimento, diz o negro, termina por deixar o
homem de cor sem ajuda, pela preferência dada ao estrangeiro, sem
nada fazer para diminuir a espantosa mortalidade do homem negro
sobretudo a infantil, nem para suprimir os cortiços em que as
moléstias infecciosas se desenvolvem com uma rapidez
desconcertante, e que a tuberculose reina. Quanto mais depressa
morrem os negros mais depressa o país se tornará branco. E o
branco responde: tínhamos uma solução suave e bem dentro da
nossa tradição democrática, pouco a pouco os sagues se mesclavam
e o negro diluía-se na massa branca [...]

A necropolítica também não estaria ausente das políticas totalitárias. Uma vez que preconceito, discriminação e racismo funcionam como chaves indispensáveis de uma política de gestão de vida pela morte, o que acionam é sempre a arbitrariedade do terror como instrumento necessário de imposição igualmente política, ao passo que não pesa a destruição da dignidade humana. Se Arendt (2020 a, p. 53) argumentava que nos totalitarismos "a discriminação se transformava em argumento político", poderíamos afirmar que na necropolítica quando a discriminação se transforma em argumento político, a morte é mera alegação na manutenção do próprio instrumento político. O que Nascimento (2016) comprova como o genocídio do negro brasileiro se circunscreve nesse campo.

Ao objetivarmos a publicação do presente dossiê, intentamos justamente colocar em cena uma série de investigações cujos desafios e cujas abordagens, problematizações e experimentações levem em consideração esse amplo espectro da necropolítica. Entretanto, ao enfatizarmos os lugares das infâncias contemporâneas em tal cenário, sublinhamos o complexo nódulo que as crianças negras ocupam na necropolítica. Numa via, pelo fato de serem, contra suas vontades, capacidades humanas e decisões, herdeiras de uma situação históricosocial de matriz necropolítica. As crianças negras, assim, nascem territorializadas num contexto necropolítico inequívoco. Em outra via, as crianças compõem relevante aceno na formação de estratégias de tensão e de modificação nos quadros necropolítico. A nosso ver, as crianças aprendem a ser racistas, desde a mais precípua socialização, na ampla lógica necropolítica e, portanto, também podem aprender a não ser racistas. Indagar por outros possíveis, tomando por centralidade 
pensar outros possíveis entre infâncias e necropolíticas

as crianças, é atentarmos para toda experimentação que as crianças são capazes de empreender como desterritorialização necropolítica.

Não se trata de utopia rasteira e de pragmática ingênua. A questão, apesar de óbvia, não é simples: as crianças negras sofrem imediatamente as consequências necropolíticas cristalizadas nas camadas da banalização violenta de nossa sociedade. Muitas são mortas, raptadas, violentadas e desaparecidas brutalmente sob um jogo normalizador e desprovido de consolo político. A intervenção imediata na necropolítica deve começar pelas e nas infâncias das crianças, como corte profundo num ciclo que precisa ser rompido. Não imputamos às crianças responsabilidade nesse jogo de transformação. Mas não deixamos de considerar as crianças como a potência de grau zero em vias pela qual a necropolítica deve cessar por completo e sem retorno. É certo, porém, que toda sociedade é responsável por preservar as crianças da necropolítica.

Aqui uma inflexão se faz necessária. O Brasil está assentado numa cultura negacionista dos efeitos deletérios e mortíferos da necropolítica instalada ao longo de todo o seu tecido social. Na necropolítica há uma evidente "banalidade do mal", para nos valermos da expressão de Arendt (2020 b, p. 274) quando se referiu à superfície dos acontecimentos mortíferos e aterrorizantes que se disseminam no cotidiano como hábito reduzido à inevitabilidade. Negam-se que as enchentes de atrocidades que dizimam as crianças negras pela insegurança alimentar, miséria, falta de saneamento básico, violência urbana e de Estado policial, negligência, descuido, precarização das condições materiais de subsistência, exclusão sociopolítica, sem nos esquecermos das violências simbólicas de todas as ordens, sejam frutos de opções políticas e arranjos sociais sustentados na origem extorquida dos povos afrodescendentes. Poderíamos chamar isso de inconsciente racista, ou seja, o manejo em profundidade que condiciona a manifestação bipolarizada entre os que foram inferiorizados pelo embrutecimento colonial e continuam sendo ${ }^{4}$, uma vez que "é o racista que cria o inferiorizado" (Fanon, 2015, p. 90, grifos originais).

\footnotetext{
4 A cultura negacionista do Brasil possui uma infraestrutura historicamente consolidada e sistematizada pela perspectiva higienista que se aportou em conceitos como a mestiçagem como sinônimo de degeneração da raça e que justificava a violação das vidas, a projeção dos/as negros/as como menos evoluídos e, portanto, infantis é muito simbólica para pensarmos que a concepção eurocentrada de mundo, também, opõe adultos às crianças, sendo a vida destas menos relevantes
} 
Assim, quando Fanon (2015, p. 86) argumenta que o "racismo colonial não difere de outros racismos", é preciso atentar que o fundo movente a persistir é este de uma política de inferiorização. A necropolítica é a resposta radical que leva às últimas consequências a extensa prática histórica de inferiorizar grupos de indivíduos inteiros. Compreende-se também aí um papel de ordenação de normalidades com as quais se passa a conviver: do navio negreiro aos campos de concentração; das senzalas às comunidades periféricas do caos urbano; da morte por exaustão à morte por impedimento ao acesso às redes de proteção social, encontraremos o outro inferior, o outro cuja morte não ultrapassa o consenso do cotidiano necropolítico a negar dignidade humana àqueles destinados às relações de dominação e de submissão.

Se é correto que "nossa história nos assombra porque foi enterrada indevidamente" (Kilomba, 2019, p. 223), a estratégia imediata das justificativas da negação da necropolítica lança, com mãos ligeiras, recurso ao cinismo político. 2020 foi um ano em que crianças negras foram sobejamente mortas por armas de fogo, nas mais diferentes e repudiantes situações, embora saibamos que a morte não parou naquela data. Também foi ali que a criança negra Miguel Otávio, após cair do $9^{\circ}$ andar, enquanto estava sob a tutela da patroa de sua mãe, morreu brutalmente, espécie de sintoma do não cuidado e da negligência com a criança. Igualmente foi quando João Alves Freitas, homem negro, de 40 anos, foi morto de modo bárbaro em um supermercado no Brasil. Mas isso importa? A quem importa? Por que importa? Por ocasião de sua morte, o Vice-Presidente da República do Brasil anunciou: "no Brasil, não existe racismo. Isso é coisa que querem importar para aqui" (Mazui, 2020).

\footnotetext{
em uma escala de prioridades. “Os negros africanos são o que são: nem melhores nem piores que os brancos: simplesmente eles pertencem a uma outra fase do desenvolvimento intelectual e moral. Essas populações infantis não puderam chegar a uma mentalidade muito adiantada e para esta lentidão de evolução tem havido causas complexas. Entre essas causas, umas podem ser procuradas na organização mesma das raças negríticas, as outras podem sê-lo na natureza do habitat onde essas raças estão confinadas. Entretanto, o que se pode garantir com experiência adquirida, é que pretender impor a um povo negro a civilização europeia é uma pura aberração" (Rodrigues, 1957, p.114). Dessa forma, o que significa no Brasil ser uma criança e negra, significa entre outras coisas, a re-existência ao negacionismo da vida e ao impulso por outros possíveis. Assim, convergir em um giro epistemológico para tentar olhar com elas (as crianças - negras, indígenas, surdas, macumbeiras, periféricas etc.) faz-se necessário.
} 
pensar outros possíveis entre infâncias e necropolíticas

Não obstante, enquanto preparamos a apresentação deste dossiê, dois homens negros são violenta e barbaramente executados em Salvador, Bahia, por furtarem carnes de um supermercado. Ainda que implorassem para que se chamassem a política, ambos foram entregues para um justiçamento semelhante aos seus irmãos executados pela senhores da casa-grande: sem direito à justiça ou direitos humanos. Uma semana depois, uma operação policial na comunidade do Jacarezinho, no Rio de Janeiro, produz uma carnificina de vidas negras. Quase trinta pessoas são executadas com armas de fogo. A alegação de se buscar fuzis e armamentos de posse de narcotraficantes ressoa o peso das estratégias necropolíticas: enquanto nesta operação se apreenderam 6 fuzis para 28 mortes, em um condomínio de luxo, na mesma cidade, em outra operação, apreenderam-se 117 fuzis sem um tiro qualquer. Mas Jacarezinho é uma comunidade negros e negras, eis uma diferença brutal.

A necropolítica, nesse caso, enseja a continuação de toda violência colonial, porém, como negação extensiva da própria violência e a retomada de sua banalização. Daí o sentido do cinismo, ele precisa negar o que é caudatário ao jogo mortífero da necropolítica: o preconceito, a discriminação e o racismo cotidiano, sempre eivados por muita violência. Sob ímpeto de leniência epistemológica, poderíamos até conceber a negação como um mecanismo de defesa. Afinal, assumir a face violenta e legal de nossa realidade é sempre empreendimento chocante. Mas a negação, nesse caso, é muito mais forma política de conveniência à necropolítica, por duas razões.

Em primeiro lugar, com o preciso diagnóstico de Kilomba (2019, p. 13):

Uma sociedade que vive na negação, ou até mesmo na glorificação da história colonial, não permite que novas linguagens sejam criadas. Nem permite que seja a responsabilização, e não a moral, a criar novas configurações de poder e de conhecimento.

Equivale dizer que a negação da necropolítica bloqueia a própria presença viva de negros e negras como componentes individuais e coletivos fundamentais à composição social da nação. Isso já era antevisto naquele exemplo da política de branqueamento que Bastide e Fernandes (2008, p. 199, acréscimos nossos) denunciavam. A frustração dos políticos brancos com o fracasso da mescla racial para diluir o negro na sociedade estava no fato de negros e negras começarem a se mobilizar politicamente:

E eis que certos líderes [negros e negras] fazem, de seus complexos de inferioridade, doutrinas ideológicas [defesa e reivindicação de 
direitos], separam o que estava unindo [o branqueamento], introduzem um fermento de discriminação [a afirmação da negritude], de segregação [lutas por espaços e reconhecimento], com todas as suas sociedades e jornais de combate [pensamento e ação próprias]. Excitam a classe baixa [os explorados, os precarizados e os necropolitizados] contra a ordem existente [a elite branca e senhorial] e introduzem por toda parte a desordem [direito à dignidade, à igualdade social, econômica e racial], a reivindicação, a arrogância [ferramentas de dominação da colônia].

A negação da necropolítica incide também como efeito de insegurança e imaturidade social, sobretudo quando seria necessário se fazer ajustes de contas dos equívocos históricos no acolhimento, na abordagem e na consideração social dos povos afro-brasileiros. Poderíamos dizer que a tomada de consciência dos negros e das negras, como povo africano e sujeitos racializados, no Brasil, assusta a sociedade. A explicação encontra-se no poder da subversão do sadismo colonial. Ao nos afirmamos negras e negros, produzimos e reconhecermos outros possíveis. Por conseguinte, agitamos os inconvenientes assentados na comorbidade das convicções em que cada um deveria seguir ocupando o seu lugar e papel conformes a política de reaproveitamento dos negros e das negras, sempre por seus reajustamentos e ajustes à contínua política de inferiorização.

A negação da necropolítica, em segundo lugar e numa espécie de consequência que prolonga a política de negação acima, normaliza o que Mbembe (2018 a, p. 250) denominou de "violência fantasmal". Ela abrange a aceitação de estereótipos como marcadores mortíferos, em que negros e negras se reduzem a alvos prediletos de "experimentar uma condição permanente de 'viver na dor'" (Mbembe, 2018 b, p. 68). Dor encarnada no preconceito, na discriminação, no racismo cordial e cotidiano a pulsar nas discursividades e nas enunciações; na cadeia de exclusão permanente; na brutalidade somática; na execração de experiências simbólicas próprias, sobretudo as religiosas; no restabelecimento vexatório de identitarismos fascistóides: negro perigoso, ladrão, violento, assassino, vagabundo, preguiçoso, abusado; negra gostosa, bonita, negona sarada, mulata, negra que nem parece negra, negra inteligente, negra que aqui não é seu lugar, “negra do cabelo duro, que não gosta de pentear" e sucessivamente.

Quando Fanon (2015, p. 148) argumentou que “o negro é um objeto fobógeno, anxiógeno", portanto, gerador de ansiedade e medo, remarcava a 
pensar outros possíveis entre infâncias e necropolíticas

sobredeterminação de valores e de identificação que a sociedade, desde as colonizações, impôs aos povos africanos. Trata-se de uma presença latente de um marcador violento que dá suporte justificador à necropolítica. Assim, negros e negras não podem estar no lugar errado, na hora errada; suas ações não podem ser condizentes com singularidades de suas culturas, isso é demasiadamente perigoso. Portanto, há de se adorar a santa do branco, ter-se o cabelo da branca, ouvir e produzir a música do branco, desejar como o branco deseja, colonizar a sua própria subjetividade, diferença e singularidade. Tudo isso com política de negação da própria negritude, pois, apesar de tudo, o perigo é intransponível: "por onde for, um negro permanece negro" (Fanon, 2015, p. 168).

A violência fantasmal reativa a necessidade de adequação dos negros e das negras em sociedade, matando no berço da própria negritude qualquer política de inversão de valores. A necropolítica, assim, mobiliza a vida a serviço da manutenção da exploração, da opressão e das diferenças sociais. É que “a família tradicional conservou seus antigos valores de superioridade racial" (Bastide; Fernandes, 2008, p. 166). Eis que tudo se ilumina: a "violência fantasmal se baseia na negação de qualquer singularidade essencial" (Mbembe, 2018 a, p. 250). Em outros termos, a violência fantasmal da necropolítica assinala ao negro e à negra que a negritude é um modo de ser muito perigoso, pois as singularidades ameaçam os estertores da ordem e do progresso, dos valores que colocam Deus acima de tudo, a família heteronormativa e patriarcal como irradiação da segurança social, a pátria acima de todos - pátria a(r)mada colonial.

Mas não estaríamos carregando demais na tinta? Por que essa ênfase toda nos negros e nas negras? Não estariam os povos indígenas também sobre a mesma ameaça da necropolítica, aliás anterior mesmo à chegada dos africanos na colônia? Não estariam aí, para além das vidas negras, aquelas vidas precarizadas, marginalizadas e expulsas da seguridade social? Seguramente que sim. A perspectiva, porém, não pode ser de negação da ponta mais vibrante por onde a necropolítica ressoa. Em uma sociedade cuja composição é majoritariamente de afrodescendentes; cujos assassinatos por forças policiais ressaltam como negras e negros são as vítimas, de longe, preferenciais; quando o sistema prisional é ocupado 
majoritariamente por negros; quando as comunidades das conurbações estão tomadas de modo maciço pelos afrodescendentes; ou por termos diante de nosso nariz um relatório escandaloso da Comissão Interamericana de Direitos Humanos da Organização dos Estados Americanos - OEA demostrando por que o Brasil é um país racista e violento (Cidh, 2021), capaz de fazer da necropolítica instrumento de limpeza social, a razão não se furta ao que se constata a olho nu.

Esse escrutínio nos permite enxergar como se perpetua "o sistema de acomodações raciais herdado do passado" (Bastide; Fernandes, 2008, p. 229) que, à luz da necropolítica, revigora todo trauma colonial, insidiosamente destinado aos negros e às negras, desde que sabemos que

ninguém colonializa inocentemente, que também pouco ninguém colonializa impunemente; que uma nação que colonializa, que uma civilização que justifica a colonização e, portanto, à força, já é uma civilização enferma (Césaire, 2010, p. 26).

Com efeito, a necropolítica é uma estratégia inequívoca da barbárie instalada numa civilização enferma. Tal barbárie é suposta no manejo eficiente da morte, reestabelecendo territórios de poder que funcionam como guetificação contemporânea, espécie de marcador de controle político e econômico, alheio a qualquer possibilidade de restituição ou reparação de justiça. A necropolítica, assim, segue deixando na história lesões e marcas profundas de segregação. Ela ainda assinala persistentes traços que precisam ser denunciados incansavelmente, pois, nos termos de Mbembe (2018 a, p. 314),

O processo histórico foi, para grande parte da humanidade, um processo de habituação à morte do outro - morte lenta, morte por asfixia, morte subida, morte delegada. Essa habituação à morte do outro, daquele ou daquela com quem se crê nada compartilhar, essas formas múltiplas de esgotamento das fontes vivas da vida em nome da raça ou da diferença, tudo isso deixou vestígios muito profundos, quer no imaginário e na cultura, quer nas relações sociais e econômicas. Essas lesões e marcas impedem fazer comunidade. De fato, a construção do comum é inseparável da reivindicação da comunidade.

Face à necropolítica, pensar outros possíveis emerge neste dossiê como mobilização de nos constituirmos como comunidade outra. Se as crianças encontram aqui lugar de destaque é porque a vitalidade dessa comunidade necessita da mesma vitalidade pulsante e inegociável das crianças. Ao mencionar 
pensar outros possíveis entre infâncias e necropolíticas

que "precisamos atentar muito bem nos modos pelos quais as crianças brancas entram em contato com a realidade do negro", Fanon (2015, p. 168) punha em destaque as dificuldades de tais crianças verem e se verem no sentido comum de uma comunidade negra. Sem isso, persistirá a segregação, ainda que psíquica.

O mesmo pode ser extraído do diagnóstico de Kilomba (2019, p. 154, grifos originais):

Antes de uma criança negra ter lançado o olhar para uma pessoa branca, ela já foi bombardeada com a mensagem de que a branquitude é tanto a norma quanto superior, diz Fanon. Revistas, quadrinhos, filmes e televisão coagem a criança negra a se identificar com os outros brancos, mas não consigo mesma. A criança é forçada a criar uma relação alienada com a negritude, já que os heróis desses cenários são brancos e as personagens negras são personificações de fantasias brancas. Apenas imagens positivas, e eu quero dizer imagens "positivas" e não "idealizadas", da negritude criadas pelo próprio povo negro, na literatura e na cultura visual, podem desmantelar essa alienação.

A necropolítica, entretanto, funciona como imunizante dessa comunidade que poderia emergir. Esposito $(2002 ; 2010)$ mostrou que o sentido da comunidade está assentado na associação humana dotada de munus. A polivalência etimológica de munus denota a polivalência que toca o sentido de communitas. Pertencer a uma comunidade, estar no seu cum munus, envolve mútua pertença, partilha, concórdia e relação com tudo aquilo que o munus abrange: "cargo", "ofício", "dever", "dom”, "talento" e "graça". Por sua vez, cada um desses elementos assinala reciprocidade entre disposição individual em confiar seu munus ao comum e este em acolhê-lo como forma de fortalecimento da própria comunidade.

Resistir ao comunitário implica com o surgimento daqueles que, fora do pacto do munus, tornam-se figuras imunes ao sentido valorativo comum. Os imunes são os immunitas, isto é, os que não têm, os que não querem ter ou aqueles a quem foram negados e privados do munus. Toda comunidade se fortalece reforçando seu sentido comum enquanto se desvia dos que se pretendem imunes a ela, além de se ter em consideração estratégias que visem a abordar a refração ao munus para, então, permitir o seu acesso à comunidade. Paradoxalmente, a comunidade se imuniza contra os immunitas; e os immunitas precisam ser imunizados contra a sua imunização. 
Neste período pandêmico em que se fala sobejamente em imunização, é mais que urgente imunizar as crianças da necropolítica, pois o mundo adulto já transita, aos trancos e barrancos, com a necropolítica do dia a dia. Sem isso, nenhuma descontinuidade histórica entre a política da morte é possível de ser feita. Para nós, educadores e educadoras, outros possíveis para uma comunidade de vida, comovida por políticas de afetos, sensíveis às singularidades e diferenças humanas, produzindo valores para além da cova profunda da herança maldita colonial, isso não se faz sem a educação. O sentido deste dossiê está nessa direção.

Da educação formal à informal e não-formal; da pedagogia cultural impregnada pelos agenciamentos capitalistas de consumo e de padronização comercial, responsáveis pela construção corporativa da infância até o currículo escolar (Carvalho, 2013; Kincheloe, Steinberg, 2001); das cadeias discursivas que manejam políticas de afirmação sociais inclusivas; enfim, das riquezas simbólicas e expressivas do povo, as experiências com as múltiplas possibilidades de formação se delineiam como horizonte comunitário que aposta na vida e não na necropolítica. Esse deve ser um quinhão de munus inegociável na relação outros possíveis em outras vidas fazendo-nos outra comunidade humana.

A sucessão dos artigos que vocês têm em mãos neste dossiê apresenta, por perspectivas múltiplas e diferentes, com abordagens peculiares e preocupações próprias, tonalizando ênfases variadas e originais, um esforço coletivo de produzirmos uma comunidade educativa cúmplice com as infâncias e tantas possibilidades de territórios existenciais que elas fazem emergir.

Em "Dar infância a infância. Notas para uma política e poética do tempo", Carlos Skliar e Daniel Brailovsky apresentam a construção de uma política e uma poética do tempo. Pautados em expressões estéticas e éticas, inspiradas por Mia Couto, tangenciam a questão da discrepância entre crianças e infâncias no contexto de uma época governada pelos atributos da aceleração, da autoaprendizagem, do conhecimento proveitoso, do privilégio do cérebro, da divisão entre carência e abundância. Seria todo referido contexto o desdobramento de uma política que procura forjar indivíduos exitosos, sob uma relação unívoca entre o saber, o utilitarismo e a exigência de rendimento. Ao apontarem, contudo, para uma política 
pensar outros possíveis entre infâncias e necropolíticas

e poética do tempo outro, vemos emergir uma infância cúmplice com a vida. As consequências para uma educação contranecropolítica é possível de se ver delinear a partir daí.

Para Eduardo Resende Melo e Flavia Inês Schilling, no artigo "A infância e o (in)dizível: poder ubuesco, resistência e a possibilidade da justiça", a criança ao ser apresentada como possibilidade de justiça de forma eloquente e contextualizada no debate foucaultiano sobre verdade, justiça e o lugar do dizível, faz emergir certa (in)dizibilidade no cerne do direito. Tal questão se estende na compreensão resistente da infância a ser situada para além da monstruosidade presente no poder ubuesco. Para tanto, o texto toma a resistência kynica sob a chave orientadora para se pensar outra infância. Aqui já antevemos que necropolítica é um exercício ubuesco de poder e, como tal, deve ser enfrentado, visando a possibilidade da justiça para a própria infância.

Com Cristina Teodoro e Nilma Lino Gomes, em "Do poder disciplinar ao biopoder à necropolítica: a criança negra em busca de uma infância descolonizada", é possível, após a análise dos marcos legais nacionais, defender que o princípio de outra infância para a criança negra emerge senão a partir de um devir-outro. As autoras mobilizam-se para afirmar uma nova abertura de mundo e, sobretudo, uma descolonização da infância para as crianças pertencentes ao grupo etnicorracial negro. É inegável constatar o impacto que tal perspectiva aporta para o campo da educação.

Em "Necropolítica, governo sobre as infâncias negras e educação do rosto", Divino José da Silva, Jonas Rangel de Almeida e Pedro Ângelo Pagni investigam a recorrência do racismo e do preconceito sobre as vidas e as infâncias negras. Aportados na compreensão de biopoder de Foucault, os autores problematizam as peculiaridades do preconceito racial brasileiro, evidenciando a sua face necropolítica. Tal face se encontra de modo mais acentuado no tratamento das artes de governar dispensadas às infâncias e à educação dos rostos negros. $\mathrm{O}$ artigo anuncia a necessidade de um movimento de desrostificação em que o devir repercute as infâncias e, simultaneamente, os rostos negros. No caso dos rostos negros, está em jogo uma clandestinidade capaz de se insurgir contra as ordens 
majoritárias do homem-branco-heterossexual-cristão-europeu e, portanto, capaz de criar processos de subjetivação em que possam aliar a multiplicidade de outros devires minoritários consigo mesmo.

A pesquisadora Vanessa Martins nos apresenta o artigo "Sobrevida da infância surda numa sociedade centrada na língua oral: o caso da COVID-19 e a viralização das LIBRAS". Trata-se de analisar o projeto \#CasaLibras de atenção virtual em Libras às crianças surdas. A partir da produção de vídeos com contações de histórias infantis diretamente em Libras, o texto vai deslindando um lócus de análise acerca do cenário político atual. Ao mesmo tempo, o texto aporta problematizações e avanços acerca das concepções filosófico-sociais da surdez, ao passo que denuncia a ausência de políticas públicas, sociais e educacionais para a surdez. Tudo isso é elaborado considerando o contexto da necropolítica por meio da qual se afirma a produção da morte. Apesar de certa viralização da Libras na pandemia, a promoção da acessibilidade de crianças surdas está longe dos desafios que elas encontram na própria necropolítica.

Com o pesquisador Valter Roberto Silvério, em “The Brownies' Book: Du Bois e a construção de uma referência literária para identidade negra infanto-juvenil", é possível conhecer estratégias discursivas e práticas de desracialização propostas para "os filhos do sol", como W.E.B. Du Bois nomeava as crianças negras. A partir das produções do referido autor, o pesquisador Valter Silvério destaca a chave da infância negra para compreender conceitos históricos como o de auto-realização, cidadania cultural e luta negra. Com a análise de imagens dos livros e das revistas voltados à consciência racial, percebe-se o contraste com o universalismo eurocêntrico face ao pluralismo cosmopolita em que as crianças negras são representadas como cidadãs do mundo, pertencentes a uma comunidade global que reconhece as diferenças e valoriza a memória cultural e política negra.

Por fim, o artigo "O erêe e devir-criança negro: outros possíveis em tempos necropolíticos", de Alexandre Filordi de Carvalho e Ellen Souza, investiga como a noção de devir-criança negra, intermediada pela experiência do erê no candomblé nagô, suscita outros possíveis existenciais para as crianças em tempos necropolíticos. Para tanto, os autores anunciam que as crianças negras são 
pensar outros possíveis entre infâncias e necropolíticas

marcadores de singularidades sociais potentes para se alterar a lógica dos coeficientes mortíferos que perpassam a necropolítica atual, bem como o carrego colonial. Assim, no giro potente do erê, a resistência a toda e qualquer prefiguração de papéis e representação estática de vida advém de agenciamentos de devires "africamíticos", bem como suas condições para se criar outros possíveis com o intuito de se fazer reexistir as infâncias em tempos necropolíticos.

O dossiê se tece coletivamente como um território de diálogo ao redor de outros possíveis desejados, forjados e experienciados por pesquisadoras e pesquisadores negras/os e não negros, tendo como centro crianças e infâncias. No âmbito da necropolítica, os vários tipos de violências e mortes que tocam as crianças brasileiras não podem ser esquecidos, calados, minorados ou superados sem trauma. De cada criança emana um grito lancinante. Elas pulsam estrepitosamente em nossas vidas, em nossas palavras, com nossos ofícios e vontades de educação.

Nesse contexto, é impossível pensar qualquer experiência com educação sem contar com os sonhos de estudos anunciados por crianças estúpida e barbaramente ceifadas de nossa sociedade. Cada uma delas é sinônimo de dor, de fragilidade, de flor que não teve tempo de se frutificar, de vida que não colheu a primavera em decorrência da foice abrupta da necropolítica. Agatha Félix, João Pedro e Miguel Otávio, assim como Fernando Henrique, Alexandre e Matheus nos indagam acerca do papel do "Estado Democrático de Direito" no que tange à segurança social. Eles estapeiam as faces cínicas da burocracia que não ousa se corar de vergonha diante da vulnerabilidade recorrente de todas crianças que nos murmuram, procurando em nós cumplicidade: “Olhem por nós!"; “Nós estamos aqui!”; “Nossas vidas importam!”; “Salvem-nos da morte!”.

Mas isso não é tudo. Emily Vitória e Rebeca Beatriz seguem nos indagando sobre o "direito de brincar" e de ocupar as ruas sem medo e livremente, ainda reverberando os meninos de Belford Roxo: crianças desaparecidas, dragadas pelos ralos da necropolítica, reduzidas a um frio cálculo demográfico mortífero. E o que dizer de Henry Borel, espancado até a morte, nos convocando a refletir sobre o tempo da "justiça" e a justiça no tempo que Deus é colocado acima de tudo, em nome da "boa" família tradicional brasileira. 
São essas e outras crianças autoras de outros possíveis. Nelas estão também o sentido de uma sociedade que se quer justa, equânime, democrática e igualitária, pois isso não ocorrerá sem tomá-las como bússola orientadora de outros possíveis para além da necropolítica. É este dossiê, portanto, também uma homenagem e reconhecimento a elas, hoje, ancestralizadas, unidas a tantas crianças cujo sangue mancharam as vestes de Iemanjá na cruzada do Atlântico, ao longo dos quatro séculos de escravidão. Acolhidas como futuro próximo desde um presente que clama por ser outro, essas crianças fortaleceram o "quilombo do futuro" 5 , na síncope dos nossos tambores, textos, conceitos, falas e corpos. Com essas crianças e para TODAS as crianças, este dossiê se deslinda como uma tarefa colossal do inventário do real, porém, também como ensaio de mobilização geral para outros possíveis.

\section{referenciais}

Arendt, Hannah. Origens do totalitarismo. Antissemitismo, imperialismo, totalitarismo. São Paulo: Companhia das Letras, 2020 a.

Arendt, Hannah. Eichmann em Jerusalém. Um relato sobre a banalidade do mal. São Paulo: Companhia das Letras, 2020 b.

Bastide, Roger; Fernandes, Florestan. Brancos e negros em São Paulo. São Paulo: Global, 2008.

Carvalho, Alexandre Filordi de. "Foucault e o neoliberalismo de subjetividades precárias: incidências na escola pública brasileira". Revista Artes de Educar. V.6, n. 3, p. 935-956, 2020.

Carvalho, Alexandre Filordi de. Educação e imagens na sociedade do espetáculo: as pedagogias culturais em questão. Educação e Realidade Edição eletrônica, v. 38, p. 587-602, 2013.

Césaire, Aimé. Discurso sobre o colonialismo. Florianópolis: Letras Contemporâneas, 2010.

Comissão Interamericana De Direitos Humanos. Situação dos direitos humanos no Brasil. Organização dos Estados Americanos: OEA, 2021.

Esposito, Roberto. Immunitas: protezione e negazione della vita. Turim: Einaudi, 2002.

Esposito, Roberto. Bios. Biopolítica e Filosofia. Lisboa: Edições 70, 2010.

Fanon, Frantz. Peau noire, masques blancs. Paris: Seuil, 2015.

Federici, Silvia. O ponto zero da revolução. Trabalho doméstico, reprodução e luta feminina. São Paulo: Elefante, 2019.

Hosang, Daniel Martinez; Lowndes, Joseph. Producers, parasites, patriotes. Race ande the new right-wing politics of precarity. London/Minneapolis: University of Minessota Press, 2019.

Kilomba, Grada. Memórias da plantação. Episódios de racismo cotidiano. Rio de Janeiro: Cobogó, 2019.

Kincheloe, Joe L.; Steinberg, Shirly R. Cultura infantil. A construção corporativa da infância. Rio de Janeiro: Civilização Brasileira, 2001.

Mayer, Jane. Dark money. The hidden history of the billionaires behind the rise of the radical right. New York: 2017.

\footnotetext{
${ }^{5}$ Analogia ao samba enredo do ano de 2019 do "Grêmio Recreativo, Cultural e Social Escola de Samba Vai-Vai" intitulado Quilombo do Futuro.
} 
pensar outros possíveis entre infâncias e necropolíticas

Mazui, Guilherme. No Brasil, não existe racismo', diz Mourão sobre assassinato de homem negro em supermercado. G1. 20, 2020. https://g1.globo.com/politica/noticia/2020/11/20/mourao-lamenta-assassinatode-homem-negro-em-mercado-mas-diz-que-no-brasil-nao-existe-racismo.ghtml

Mbembe, Achille. Crítica da razão negra. São Paulo: N-1, 2018 a.

Mbembe, Achille. Necropolítica. São Paulo: N-1, 2018 b.

Mões, Malu. A cada real ganho por um homem branco, uma mulher negra recebe $\mathrm{R} \$ 0,43$. Poder 360. 09, mar. 2021. https://www.poder360.com.br/economia/a-cada-realganho-por-um-homem-branco-uma-mulher-negra-recebe-r-043/

Nascimento, Abdias. O genocídio do negro brasileiro. São Paulo: Perspectiva, 2016.

Rodrigues, Raymundo Nina. As Raças Humanas e a Responsabilidade Penal no Brasil. Salvador: Livraria Progresso, 1957.

recebido em: 12.04 .2021

aprovado em: 10.05 .2021 